\title{
IMPACT OF EDUCATIONAL LEADERSHIP STYLES ON JOB TEACHERS STRESS
}

\author{
Ferit Hysa \\ Department of Education \\ European University of Tirana, Albania \\ ferithysa@gmail.com
}

\begin{abstract}
During the school management, it is very important to have an effective school but more important is to use the right styles according to health safety and high outcomes. The leadership is a wide concept in general way and a specific one according to the education and school too. The tradition of school leadership is new in Albania. The education leadership in the new Albanian context request establishing of school leadership. The knowledge and application of contemporary education leadership it is obligatory for improvement and raising effectively to Albanian school. This study is focus in the influence of educational leadership styles in the job teachers stress and satisfaction. The research question is: what is the best and right education leadership style need to be applied in Albanian school. The research method is a quantities and qualitative way through the questionnaires, semi and structures interviews. The conclusion is that no all the educational leadership styles that are effective ones, are the right educational leadership styles. This conclusion brings the need to be selected the educational organizational theories for an effective school through the right educational leadership styles.
\end{abstract}

Key words: leadership style, education, stress, satisfaction, effective school.

\subsection{Introduction}

The development of education in Albania has gone growing and expanding from year to year. After 90 years, the development of education has faced new challenges in terms of improving programs, teaching methods as well as the continued growth of not only the students who attend secondary school, but also universities. Such an education, mass appeal seeks a more effective based on theories and best practices of the western world. Therefore the aim of this study is to identify the impact of school leadership styles and styles promote more effective in managing the impact of which school is low in teacher stress and also increase job satisfaction of teachers.

The objectives of this study are to: Identify the best styles of school leadership that have the lowest impact on job stress in teachers and those who increase their job satisfaction.

- Identify leadership styles of school leaders through the teacher's view.

- Identify the level of stress among teachers

- To identify whether there is a significant connection between the leadership styles of leaders and teacher stress.

- Identify the level of satisfaction of teachers

- To identify whether there is a significant connection between the leadership styles of leaders and teacher satisfaction.

In this study we pay attention to a state psychological stress and physical health damage for which recently received the deserved attention and has attracted attention. Identify stressors in the work of teachers.

Stressor is what makes possible the occurrence of stress.

Precisely in this study we have obtained a numerous studies that need to be made concerning it, it's just related to the impact of leadership styles school.

The state of stress affects the health of teachers but also affects the job performance of teachers. 
Likewise, job satisfaction of teachers has its importance as the health of teachers and the performance of his work.

There is a clear correlation between stress and job satisfaction of teachers and both of these effects on the efficiency of the work of teachers.

Recognition of the impact of school leadership styles in stress and job satisfaction of teachers would make it possible to avoid the negative impact styles and promoting them as a positive impact on the health of teachers and the effectiveness of the work of teachers in the school.

\section{Literature review}

\subsection{Introduction}

In this session we will first consider an overview of the basic styles of leadership, the concept of leadership in organizational theory and the differences between management and leadership and then consider the aspects of leadership that appear to be particularly relevant to an international educational environment. These include:

- $\quad$ the importance of vision;

- the benefits of transformational leadership;

- $\quad$ placing the education of pupils and students at the forefront of planning and managing;

- $\quad$ the moral or ethical dimension of leadership in education;

- the increasing autonomy of schools and colleges in some countries, placing new and different responsibilities on educational leaders;

- gender and leadership, particularly as qualities of leadership are generally identified with the male (Schein, 1994).

\section{Transformational and transactional leadership}

The principal who practices transformational leadership is not relying only on his or her personal charisma or a series of leadership functions, but is attempting to empower staff and share leadership functions. Transformational leadership may be contrasted with transactional leadership which is:

based on an exchange of services (from a teacher, for example) for various kinds of rewards (salary recognition, and intrinsic rewards) that the leader controls, at least in part. (Leithwood, 1992, p. 69)

However, Bass and Avolio (1994) offer a two factor theory of leadership where transformational leadership may exist alongside transactional leadership, which is seen to be central in maintaining the organization and ensuring that the normal course of events run smoothly. Transformational leadership is specifically linked with the notion of improvement. Bass and Avolio (1994) state that transformational leadership is seen when leaders:

- 'stimulate interest among colleagues and followers to view their work from new perspectives,

- generate awareness of the mission or vision of the team and organization,

- develop colleagues and followers to higher levels of ability and potential, and

- motivate colleagues and followers to look beyond their own interests toward those that will benefit the group.'

(Bass and Avolio, 1994, p. 2)

Alternatively, they refer to transformational leadership as the four i's: 
1. Idealised influence, leaders are seen as role models for others;

2. Inspirational motivation;

3. Intellectual stimulation;

4. Individualised consideration, including leaders acting as coach or mentor to individuals in the institution.

As indicated above, leadership is situational, i.e. leaders may exhibit different styles and aspects of leadership depending on the specific context within which they are operating. However, those leaders who display, what is termed, 'an optimal leadership profile' exhibit transformational leadership and back up their transactional leadership with positive reinforcement and reward rather than correction. Bass and Avolio (1994) found that research undertaken in all walks of life indicated that transformational leaders:

'were more effective and satisfying as leaders than transactional leaders, although the best of leaders frequently do some of the latter but more of the former.' (ibid., pp. 5-6)

Studies in educational institutions have indicated that transformational leaders appear to be: 'in continuous pursuit of three fundamental goals:

1) helping staff members develop and maintain a collaborative, professional school culture;

2) fostering teacher development; and

3) helping them solve problems together more effectively.' (Leithwood, 1992, pp. 69 - 70)

Burns (1978) is credited with first identifying transformational leadership. He does not endorse the two-factor theory of leadership, but rather considers transformational leadership to be at the opposite end of the spectrum from transactional leadership. This represents a very different view of transformational leadership to the two-factor theory of leadership, where transformational and transactional leadership may be identified in a single person (Bass and Avolio, 1994).

Conclusions about transformational leadership are drawn from a wide range of studies, both quantitative and qualitative, but Leithwood et al (1996) note that there are positive effects associated with several identified forms of leadership in education.

\subsection{Stress}

Psychological or biological stress (wikipedia 2014) is a response of the body to stress shktarëve as an environmental condition or incentive. Stress is the body's reaction methods to challenge stressors. In accordance with stressful events, how the body respond to stress by activating the sympathetic nervous system which results in response to the war effort.

In humans, stress usually reveals a negative or a positive condition that may have an impact on a person's mental or physical welfare of his.

Three general ways to answer (response) to stress are:

- Explosive

- Withdrawn, lonely

- Chilled, frozen, unresponsive with no response. 


\section{Methodology}

In this study we used quantitative and qualitative methods of research. Through structured interviews and semi-structured data are derived empirically that were analyzed. This study population consists of middle school teacher of 9 years. 30 teachers were interviewed. Through interviews is intended to identify the leadership style of management, the impact of their actions on teacher stress and stress doing overall situation of teachers. During the interview was aimed to identify other factors influencing the stress of teachers to determine whether the stress comes from the leadership style or other factors to be as accurate on the impact of leadership.

Questionnaires were made simultaneously at about 100 teachers who have voiced their opinion regarding the impact of leadership in their stress developed in 10 schools. In each school were 10 questionnaires and interviews Random 3.

Also become a document study of training and experience of current directors to see the correlation between experience, training and leadership style that uses school leader.

\section{Data Analysis}

Stress has been described by the HSE as "the adverse reaction people have to excessive pressure or other types of demand placed upon them". Although stress itself is not a disease, it is recognised that excessive or prolonged stress can be a cause of mental and physical illness.

HSE research has found that one in five people - an estimated 5 million workers - is 'very' or 'extremely' stressed at work, and that stress, anxiety and depression nationally lead to more than 13 and a half million lost working days each year. The International Labour Organisation has estimated that the cost of stress to the British economy amounts to over ten per cent of its Gross National Product (GNP).

Studies into the extent of work-related stress in Britain have consistently found that teachers are amongst the most stressed workers in Britain.

HSE research in 2000 found teaching to be the most stressful profession in the UK, with $41.5 \%$ of teachers reporting themselves as 'highly stressed'.

In 2003 a study undertaken by the Schools Advisory Service, the largest independent provider of teacher absence insurance in the UK, showed that one in three teachers took sick leave in the previous year as a result of work-related stress.

A survey on occupational stress, published in the Journal of Managerial Psychology in 2005, ranked teaching as the second most stressful job out of 26 occupations analysed, with only ambulance drivers exceeding the stress levels found in the teaching profession.

According to the Office for National Statistics, there was an 80 per cent increase in the number of teachers committing suicide between 2008 (35 teachers) and 2009 (63 teachers). These figures demonstrated that instances of suicide for teachers were 30-40 per cent higher than the national average for all occupations. Although it may not always be possible to demonstrate a direct causal link between the stresses of teaching and such tragedies, evidence suggests that stressors such as Ofsted inspections have been connected to teacher suicides in recent years.

In April 2009, Teachers TV surveyed 1000 teachers and found that more than half had considered leaving the profession because of stress. Meanwhile, a survey of teachers conducted by the NUT and others in 2010 found that 81.2 per cent experienced stress, anxiety or depression at work.

\section{THE CAUSES OF TEACHER STRESS}

Research evidence has shown that the main sources of the current high levels of teacher stress include:

- $\quad$ excessive workload and working hours - often exacerbated by a surfeit of government 'initiatives';

- poor pupil behaviour, which itself is often compounded by issues such as large class sizes;

- $\quad$ pressures of assessment targets and inspections; 
- management bullying; and

- lack of professional opportunities.

A study, commissioned by the NUT in 2004, and undertaken by professors Galton and MacBeath of Cambridge University, suggested that pupil indiscipline is the prime obstacle to securing improvements to teachers' lives. This lends support to the view that initiatives to reform the school workforce will only succeed in reducing teacher stress if they are fully integrated into a comprehensive range of measures which address all the root causes of stress in the teaching profession.

According to research for the TSN has indicated that the most common causes of teacher stress are, in order:

- $\quad$ excessive workload (causing stress symptoms in some 40 per cent of teachers);

- $\quad$ aggression from pupils or parents (30 per cent of teachers);

- Ofsted/Estyn (over 20 per cent of teachers); and

- $\quad$ conflict with managers or colleagues (almost 15 per cent of teachers).

Similarly, a 2008 TSN survey of teachers who had resigned or were considering resignation found that, of those whose decisions were motivated by school-based issues:

- 69 per cent blamed work-life balance/workload as a contributing factor;

- 47 per cent cited pupil indiscipline;

- 47 per cent referred to bullying by management; and

- 40 per cent identified lack of career progression.

Associated with this study (in Albania) by surveying and interviewing 100 teachers of 30 other teachers are in the schools, showed that:

$75 \%$ of teachers reported that they have stress in their work, which indicates that this job is very stressful profession in general. $57 \%$ of teachers said they would leave the profession if they could find another job. Statistics $60 \%$ of teachers have received report mjekso for 1-3 days to not go to work to relax. $40 \%$ of teachers do not want to over work to meet with the school principal. $58 \%$ of respondents state that during discussions with the principal issues remain worried after this discussion. $70 \%$ of teachers state that they are not clear about the work they do whether you like it or not their leaders. $90 \%$ of teachers declare that all instructions, orders and information received from the director himself, and $10 \%$ claim to receive from other persons specified in the management structure of the school.

$93 \%$ of teachers do not understand the level of their peer evaluation by department evaluation reports but indirect way of opinion and colleague to colleague. During their 85 teachers have experienced stress, anxiety or depression.

The data show that $70 \%$ of leadership styles that are used $30 \%$ authoritarian and democratic laiser-all.

The influence of these styles is directly in teacher stress at work. From the study it is clear that anyone who did not exercise authoritative leadership recognition and qualifications for school administration, lack of experience or a bad experience embedded in the way and the school leadership styles.

No contemporary management theories recognize that not only create job satisfaction of teachers, reduce stress levels but also increase teachers' job performance and enhance the quality of school and student results we. 


\section{Conclusions}

Data show that school leadership styles have an impact on stress and job satisfaction of teachers. Authoritarian leadership gives a positive impact on teachers' work stress and gives negatativ impact on job satisfaction of teachers. Transformative Leadership gives negative impact on job stress and gives teachers a positive impact.

Employees health teacher is very important due to the application not knowing Nail contemporary styles of leadership should not be charged aggravated health and cost burdens of society.

In conclusion it appears that not all styles are effective school leadership styles appropriate to be applied by teachers in schools. This conclusion necessitates the selection of organizational theories for an effective school education through the application of appropriate leadership styles of school.

\section{Biography}

Ferit HYSA (PhDc). Organizational Education Course lecturer NQ UET (external) and doctoral student at UET topic is in the area of leadership and management in education. Lecturer (part time) Case Management Medodologji education and research in the University "A.Xhuvani" Elbasan from 1999 to 2011. Skilled at Leicester University (UK) for Leadership and Management in Education (2005)

\section{References}

[1] Bass, B.M. and Avolio, B.J. (1994) Improving Organizational Effectiveness Through Transformational Leadership, Thousand Oaks, Sage.

[2] Bell, L. and Stevenson, H. (2006), Education Policy: Process, themes and impact. London: Routledge

[3] Blake, R.R. and Mouton, J.S. (1964) The Managerial Grid, Gulf Publishing Co. Houston, Texas.

[4] Burns, J.M. (1978) Leadership, New York, Harper and Row.

[5] Fullan, M. (1991) The New Meaning of Educational Change, London, Cassell.

[6] Halpin, A. W. (1966) A Theory of Leadership Effectiveness, New York, McGraw Hill.

[7] Hersey, P. and Blanchard, K.H. (1977) Management of Organisational Resources: Utilising Human Resources N.J. Englewood Cliffs Prentice-Hall.

[8] Hopkins, D. (1994) 'Yellow Brick Road' in Managing Schools Today, March.

[9] Hysa,F Vol 4, No 3 (2014) - Articles The Expansion of University Education and Students High Results

[10] Hysa,F. Vol 4, No 3 (2014)- Articles School Management and Leadership in Education

[11] Leithwood, K.A. (1992) 'The Move Toward Transformational Leadership' in Educational Leadership, February.

[12] Sergiovanni, T.J. (1984a) 'Leadership as Cultural Expression', in Sergiovanni, T. and Corbally, J. (eds.) Leadership and Organizational Culture, Urbana and Chicago, University of Illinois Press.

[13] Torrington, D. and Weightman, J. (1989) The Reality of School Management, Oxford, Blackwell Education.

[14] www.teachers.org.uk/files/TACKLING-STRESS-0713.doc (para 2 prill 2014)

[15] http://www.hse.gov.uk/stress/standards/index.htm (para 9 prill 2014) 